Menegon, L., and Fagereng, Å., 2021, Tectonic pressure gradients during viscous creep drive fluid flow and brittle failure at the base of the seismogenic zone: Geology, v. 49, https://doi.org/10.1130/G49012.1

Supplemental Material for:

\title{
Tectonic pressure gradients during viscous creep drive fluid flow and brittle failure at the base of the seismogenic zone
}

Luca Menegon $^{1}$ and Åke Fagereng ${ }^{2}$

${ }^{1}$ Njord Centre, Department of Geosciences, University of Oslo, Norway

${ }^{2}$ School of Earth and Environmental Sciences, Cardiff University, UK

\section{Content of this file:}

Text S1 and S2

Figures S1 to S4

Table S1

\section{Text S1: Analytical methods}

Petrography and microstructures were investigated on polished thin sections cut perpendicular to the mylonitic foliation and parallel to the stretching lineation, and perpendicular to the vein walls and parallel to the inferred opening vector of the veins. The same polished thin sections were used for EBSD analysis of quartz and for mineral chemistry analysis of chlorite.

Major element mineral chemistry of chlorite was measured with a JEOL 8200 Super Probe equipped with five wavelength-dispersive spectrometer (WDS) at the Department of Earth Sciences, University of Milan, Italy. Working conditions were $15 \mathrm{kV}$ probe current, $5 \mathrm{nA}$ current on sample, and $1 \mu \mathrm{m}$ beam diameter. Natural minerals were used for standardization, measurement times were $30 \mathrm{~s}$ on peaks and $10 \mathrm{~s}$ on backgrounds of the $\mathrm{X}$-ray lines.

Electron backscatter diffraction (EBSD) analyses were performed at the Electron Microscopy Centre of the University of Plymouth using a JEOL LV6610 SEM and a JEOL 7001 FEG-SEM. Thin sections used for EBSD were polished with colloidal silica and carbon coated. Data were acquired on a NordlysNano and a NordlysMax EBSD detector (Oxford Instruments). Working conditions during acquisition of the EBSD patterns were $20 \mathrm{kV}, 20 \mathrm{~mm}$ working distance, $70^{\circ}$ sample tilt and high vacuum. AZtec software was used for pattern indexing on rectangular grids with a step size of $2 \mu \mathrm{m}$. EBSD patterns were processed with the Channel 5 software (Oxford Instruments).

\section{Text S2: Derivation of the Mohr-Coulomb failure diagram presented in Figure 3}

The pore fluid factor $\left(\lambda_{v}\right)$ vs differential stress $\left(\sigma_{1}-\sigma_{3}\right)$ failure diagram in Figure 3 was calculated with the same approach outlined in Cox (2010), using the following assumptions and parameters:

1. The coefficient of internal friction, $\mu$, in intact rock is typically in the range $0.5<\mu<1.0$ (Jaeger and Cook, 1979); we used $\mu=0.75$ for the metaconglomerate. For the frictionally weak chlorite-rich schists, we used a friction coefficient $\mu$ of $0.3-0.5$, consistent with recent experimental results (Okamoto et al., 2019).

2. We assumed an Andersonian stress field, a thrusting regime, and a fault making an angle of $\theta_{\mathrm{opt}}$ with the maximum compressive stress $\sigma_{1}$. The angle $\theta_{\mathrm{opt}}$ corresponds to $0.5 \tan ^{-1}(1 / \mu)$. 
3. In the thrusting regime, the vertical stress $\sigma_{v}$ corresponds to the minimum compressive stress $\sigma_{3}$. In our calculation, $\sigma_{v}$ was set at $350 \mathrm{MPa}$ from available geobarometric estimates (Bergh and Andresen, 1985).

4. We used a cohesive strength $\mathrm{C}$ of $20 \mathrm{MPa}$ for the metaconglomerate, which results in a tensile strength $\mathrm{T}$ of $10 \mathrm{MPa}$. These values are within the range typical of medium- to finegrained quartz-rich metasedimentary rocks (Sivakugan et al., 2014). For the chlorite-rich schists, we used a lower cohesive strength $\mathrm{C}$ of $5 \mathrm{MPa}$, which results in a tensile strength of 2.5 MPa (value taken from Zhang et al., 2011).

The failure envelopes for extension failure, hybrid extensional failure, and shear failure were calculated with the following equations, respectively:

$$
\begin{aligned}
& \lambda_{v}=\frac{\sigma_{3}+T}{\sigma_{v}} \\
& \left(\sigma_{1}-\sigma_{3}\right)=\frac{2 C}{\sin 2 \theta_{o p t}} \\
& \lambda_{v}=\frac{\left[4 C-\sigma_{1}+4 \sigma_{3}\right]}{3 \sigma_{v}}
\end{aligned}
$$

We assumed that extension failure (equation 1$)$ occurs only for stress conditions in which $\left(\sigma_{1}-\sigma_{3}\right)$ $<4 \mathrm{~T}$, and that hybrid extensional failure (equation 2 ) only for $\left(\sigma_{1}-\sigma_{3}\right) \leq 2.5 \mathrm{C}$ for $\mu=0.75$ (Cox, 2010).

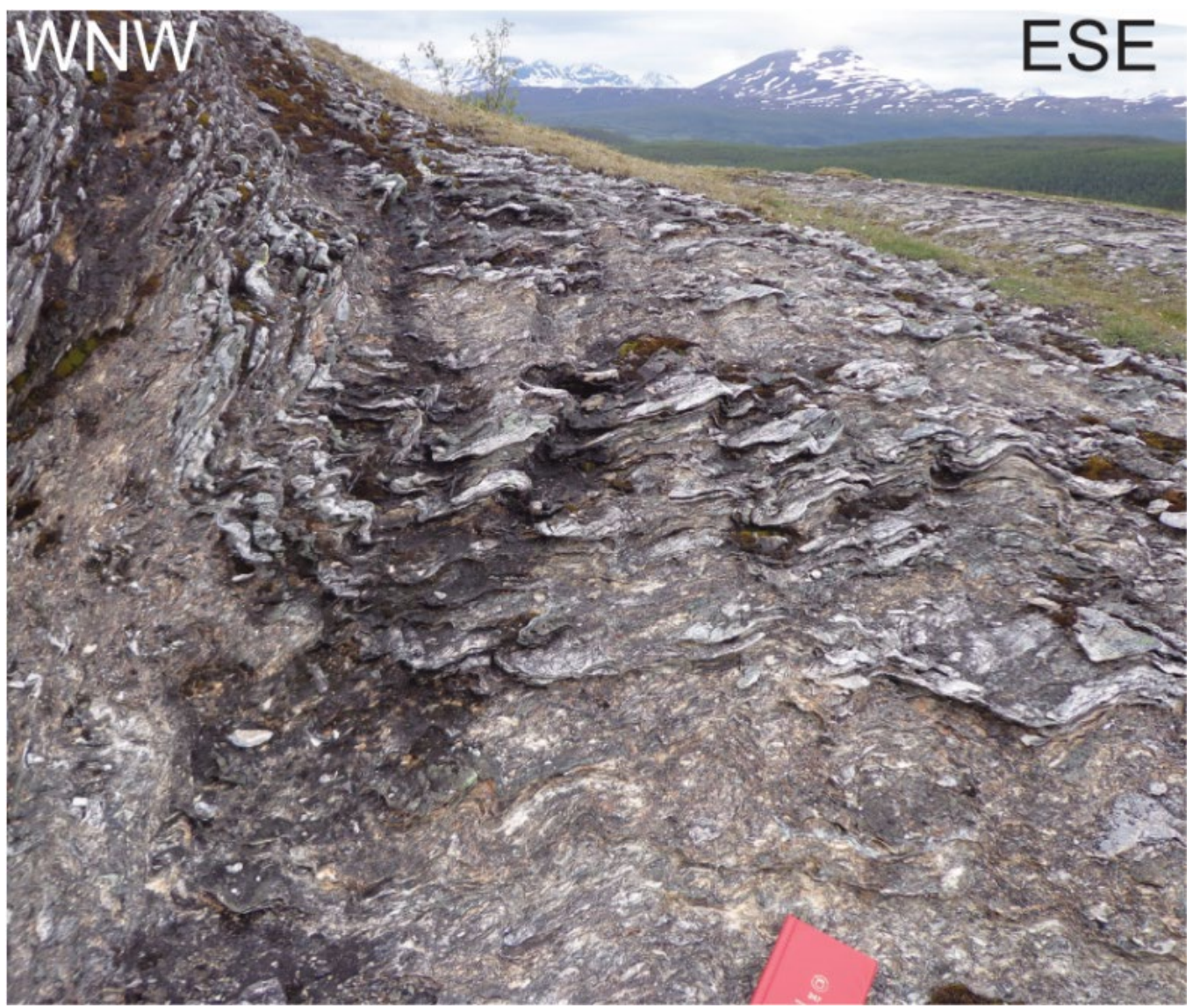

Figure S1. Field photograph showing an example of ESE-vergent folds in the Hølen Conglomerate. 


\section{(A)}

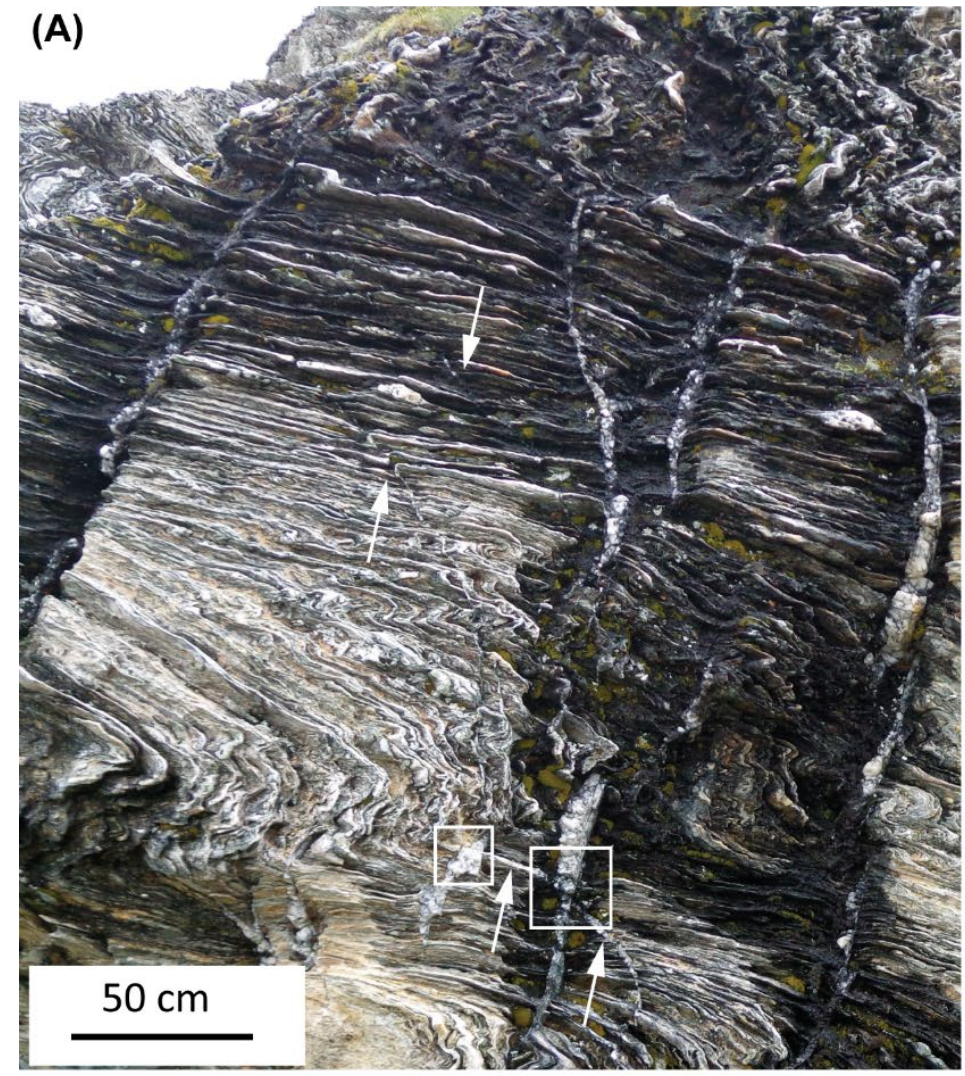

(B)
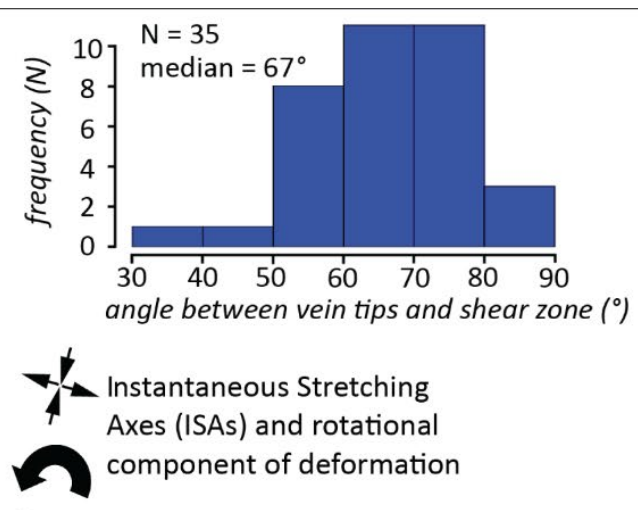

Instantaneous Stretching

Axes (ISAs) and rotational

component of deformation
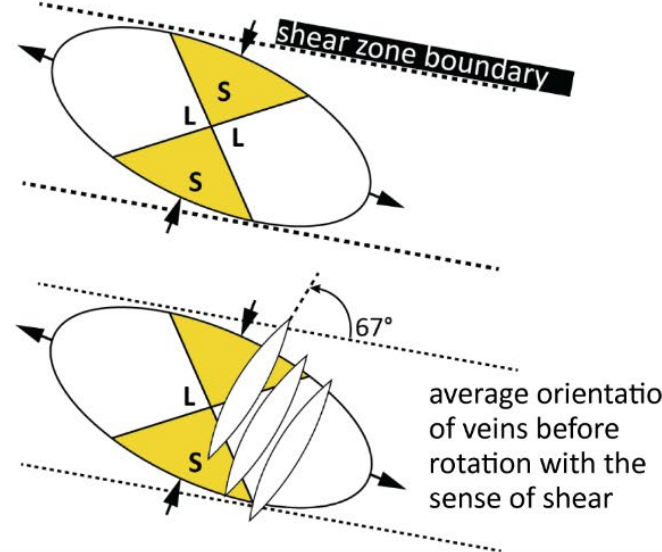

Figure S2. A. Example of crosscutting relationships between veins that experienced different degrees of rotation with the sense of shear, consistent with a cyclical generation of veins during mylonitic creep. Arrows indicate veins that experienced relatively large rotations (up to $75^{\circ}$ ). White rectangles indicate areas where these veins are cut by younger veins that experienced less rotation with the sense of shear. B. Histogram of vein tip orientation, and annotated sketches of the kinematic framework of the shear zone. 

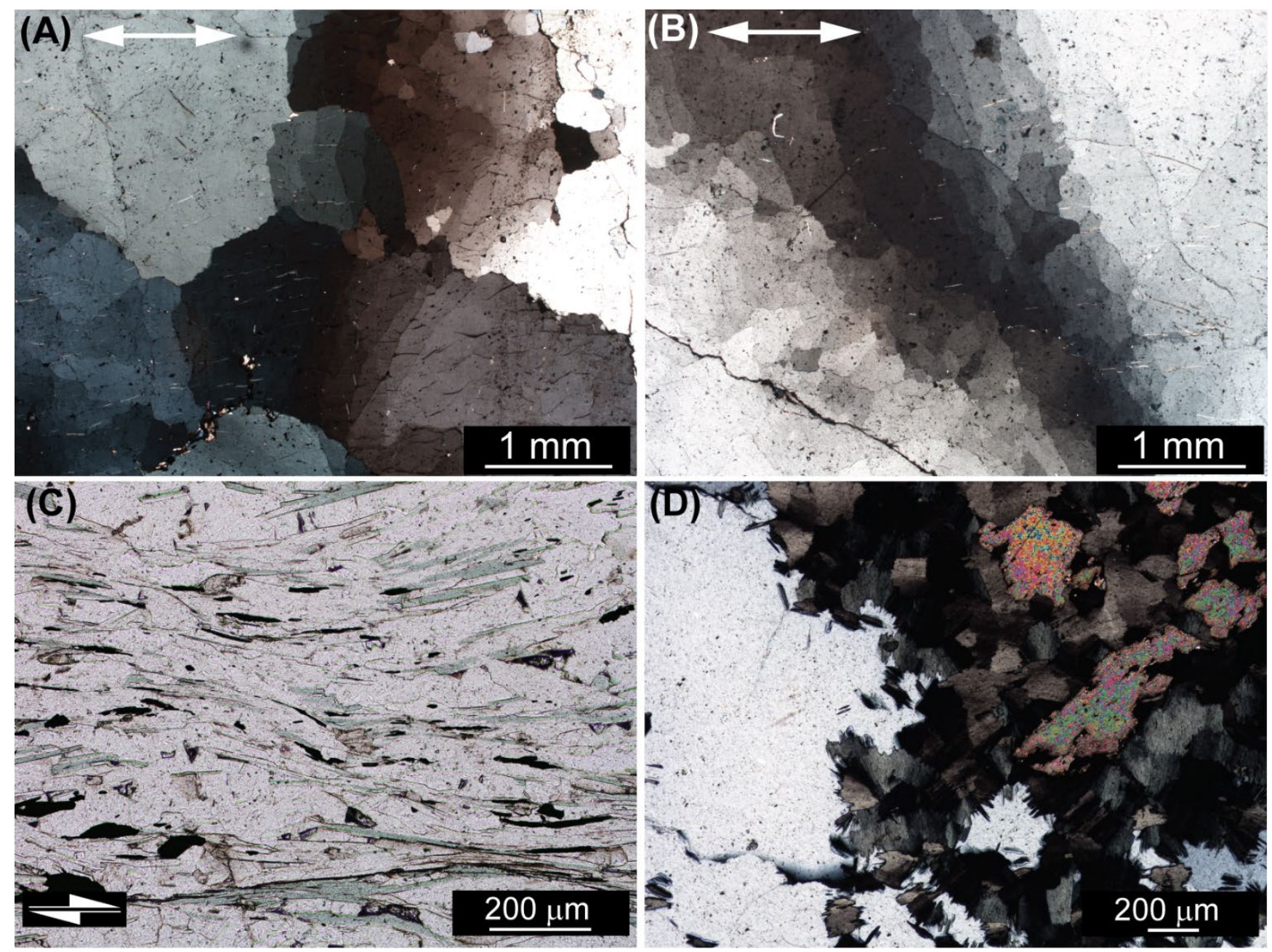

Figure S3. Photomicrographs of quartz microstructure in the sigmoidal veins (A, B) and of chlorite microstructure from sites analysed with the electron microprobe $(C, D)$. Note arrays of blocky and elongated subgrains in $A$ and $B$. White arrows in $A$ and $B$ indicate the vein opening direction. (C) $\mathrm{SC}^{\prime}$ fabric in the mylonitic schists. The dextral sense of shear corresponds to the top-to-ESE sense of shear observed in the field. (D) Syn-kinematic quartz + chlorite + carbonate vein. A, B, D: crosspolarized light. 


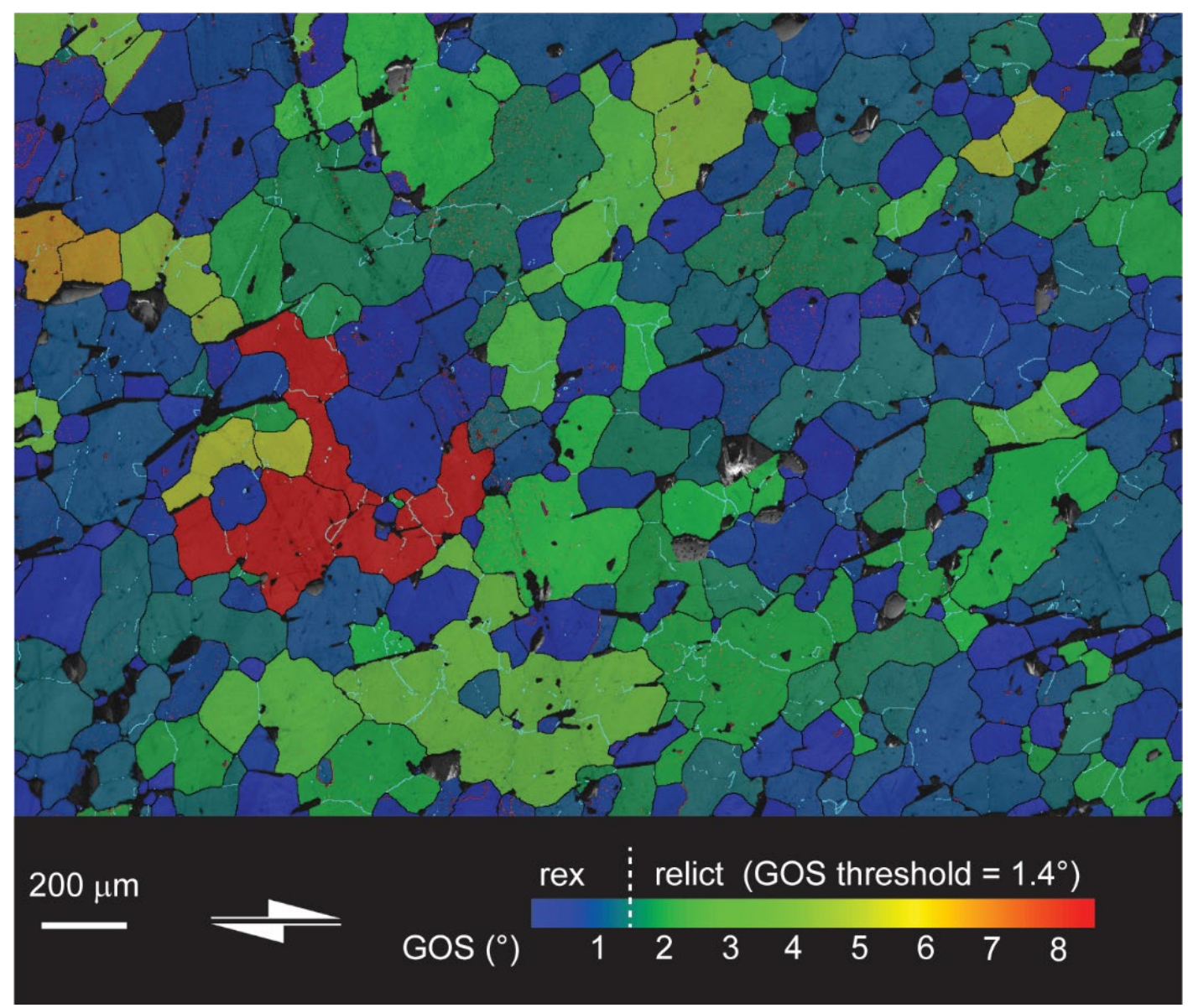

Figure S4. Additional EBSD map used for the GOS and grain size analysis of quartz. The map is color coded according to the GOS value of quartz, as indicated in the color bar. The GOS threshold to separate between relict and recrystallized quartz grains is $1.4^{\circ}$. Boundaries are color coded like in figure $2 \mathrm{D}$. 


\begin{tabular}{|c|c|c|c|c|c|c|c|c|c|}
\hline Sample & 291C & 291C & $291 C$ & 291C & $291 C$ & $291 C$ & 291D & 291D & $291 F$ \\
\hline lithology & schist & schist & schist & schist & schist & schist & vein & vein & vein \\
\hline \#analysis & LM2-chl1 & LM2-chl-2 & LM2-chl-3 & LM2-chl-4 & LM2-chl-5 & LM2-chl-6 & LM3-chl-3 & LM3-chl-19 & LM3-chl-14 \\
\hline $\mathrm{SiO} 2$ & 27,520 & 27,480 & 27,350 & 27,500 & 27,570 & 27,560 & 26,990 & \begin{tabular}{|l|}
26,750 \\
\end{tabular} & 26,100 \\
\hline TiO2 & 0,000 & 0,087 & 0,046 & 0,049 & 0,031 & 0,024 & 0,006 & 0,075 & 0,030 \\
\hline $\mathrm{Al} 2 \mathrm{O} 3$ & 23,380 & 23,750 & 23,380 & 23,510 & 23,130 & 23,680 & 23,970 & 23,530 & 23,440 \\
\hline $\mathrm{FeO}$ & 14,650 & 14,510 & 14,520 & 13,970 & 14,820 & 14,010 & 18,610 & 18,860 & 18,320 \\
\hline Cr2O3 & 0,100 & 0,065 & 0,116 & 0,050 & 0,081 & 0,074 & 0,116 & 0,129 & 0,000 \\
\hline $\mathrm{MnO}$ & 0,000 & 0,108 & 0,056 & 0,039 & 0,055 & 0,063 & 0,194 & 0,136 & 0,109 \\
\hline $\mathrm{MgO}$ & 22,170 & 22,420 & 21,880 & 22,640 & 21,690 & 22,360 & 17,900 & 19,330 & 19,040 \\
\hline $\mathrm{NiO}$ & 0,236 & 0,147 & 0,120 & 0,165 & 0,148 & 0,133 & 0,070 & 0,092 & 0,078 \\
\hline $\mathrm{CaO}$ & 0,033 & 0,031 & 0,052 & 0,050 & 0,052 & 0,133 & 0,055 & 0,030 & 0,053 \\
\hline $\mathrm{Na} 2 \mathrm{O}$ & 0,086 & 0,009 & 0,039 & 0,055 & 0,058 & 0,078 & 0,200 & 0,000 & 0,024 \\
\hline $\mathrm{K} 2 \mathrm{O}$ & 0,032 & 0,032 & 0,048 & 0,063 & 0,033 & 0,027 & 0,045 & 0,008 & 0,002 \\
\hline total & 88,207 & 88,639 & 87,605 & 88,090 & 87,669 & 88,142 & 88,157 & 88,939 & 87,194 \\
\hline \multicolumn{10}{|c|}{ structural formula based on 14 oxygen equivalent $=10$ oxygen and $8(\mathrm{OH}, \mathrm{F}, \mathrm{Cl})$} \\
\hline $\mathrm{Si}$ & 2,711 & 2,691 & 2,710 & 2,703 & 2,734 & 2,707 & 2,713 & 2,672 & 2,655 \\
\hline $\mathrm{B}$ & 0,000 & 0,000 & 0,000 & 0,000 & 0,000 & 0,000 & 0,000 & 0,000 & 0,000 \\
\hline [4]Al & 1,289 & 1,309 & 1,290 & 1,297 & 1,266 & 1,293 & 1,287 & 1,328 & 1,345 \\
\hline [6]Al & 1,425 & 1,431 & 1,441 & 1,426 & 1,436 & 1,448 & 1,554 & 1,441 & 1,465 \\
\hline [6] Ti & 0,000 & 0,006 & 0,003 & 0,004 & 0,002 & 0,002 & 0,000 & 0,006 & 0,002 \\
\hline $\mathrm{Fe} 2+$ & 1,207 & 1,188 & 1,203 & 1,148 & 1,229 & 1,151 & 1,565 & 1,575 & 1,559 \\
\hline $\mathrm{Cr}$ & 0,008 & 0,005 & 0,009 & 0,004 & 0,006 & 0,006 & 0,009 & 0,010 & 0,000 \\
\hline $\mathrm{Mn}$ & 0,000 & 0,009 & 0,005 & 0,003 & 0,005 & 0,005 & 0,017 & 0,012 & 0,009 \\
\hline $\mathrm{Ni}$ & 0,019 & 0,012 & 0,010 & 0,013 & 0,012 & 0,011 & 0,006 & 0,007 & 0,006 \\
\hline $\mathrm{Mg}$ & 3,256 & 3,273 & 3,233 & 3,317 & 3,206 & 3,274 & 2,683 & 2,878 & 2,887 \\
\hline $\mathrm{Ca}$ & 0,003 & 0,003 & 0,005 & 0,005 & 0,005 & 0,014 & 0,006 & 0,003 & 0,006 \\
\hline $\mathrm{Na}$ & 0,016 & 0,002 & 0,007 & 0,011 & 0,011 & 0,015 & 0,039 & 0,000 & 0,005 \\
\hline $\mathrm{K}$ & 0,004 & 0,004 & 0,006 & 0,008 & 0,004 & 0,003 & 0,006 & 0,001 & 0,000 \\
\hline $\operatorname{sum} X$ & 5,938 & 5,933 & 5,923 & 5,939 & 5,917 & 5,927 & 5,884 & 5,933 & 5,940 \\
\hline $\mathrm{O}$ & 10,000 & 10,000 & 10,000 & 10,000 & 10,000 & 10,000 & 10,000 & 10,000 & 10,000 \\
\hline $\mathrm{OH}$ & 8,000 & 8,000 & 8,000 & 8,000 & 8,000 & 8,000 & 8,000 & 8,000 & 8,000 \\
\hline $\begin{array}{c}\text { Calculated } T \\
\left({ }^{\circ} \mathrm{C}\right)\end{array}$ & 389 & 375 & 355 & 388 & 335 & 361 & 313 & 386 & 400 \\
\hline
\end{tabular}

Table S1. Representative analyses of chlorite composition from the schists and from the veins, used for temperature estimates using the thermometer of Lanari et al. (2014) assuming a pressure of $350 \mathrm{MPa}$. The temperature increases by $10^{\circ} \mathrm{C}$ every $50 \mathrm{MPa}$ increment in the pressure. The thermometer of Lanari (2014) requires the following conditions: $\mathrm{Si}<3$ a.p.f.u., $\mathrm{Na}+\mathrm{K}+\mathrm{Ca}<0.1$ a.p.f.u., and [( $\left.\mathrm{Al} \mathrm{VI}^{\mathrm{V}}-\mathrm{Al}^{\mathrm{IV}}-\mathrm{Na}-\mathrm{K}\right) / 2$ ] $>0.05$.

\section{References cited}

Bergh, S.G., and Andresen, A., 1985, Tectonometamorphic evolution of the allochthonous Caledonian rocks between Malangen and Balsfjord, Troms, North Norway: Nor. Geol. Unders. Bull., v. 401, p. 1-34.

Cox, S.F., 2010, The application of failure mode diagrams for exploring the roles of fluid pressure and stress states in controlling styles of fracture-controlled permeability enhancement in faults and shear zones: Geofluids, v. 10, p.217-233.

Jaeger, J.C., and Cook, N.G.W., 1979, Fundamentals of Rock Mechanics, Third edition. Chapman \& Hall, London. 
Lanari, P., Wagner, T. and Vidal, O., 2014, A thermodynamic model for di-trioctahedral chlorite from experimental and natural data in the system $\mathrm{MgO}-\mathrm{FeO}-\mathrm{Al} 2 \mathrm{O} 3-\mathrm{SiO} 2-\mathrm{H} 2 \mathrm{O}$ : applications to $\mathrm{P}-$ T sections and geothermometry: Contributions to Mineralogy and Petrology, v. 167(2), p. 968, 2014.

Okamoto, A.S., Verberne, B.A., Niemeijer, A.R., Takahashi, M., Shimizu, I., Ueda, T., and Spiers, C.J., 2019, Frictional properties of simulated chlorite gouge at hydrothermal conditions: Implications for subduction megathrusts: Journal of Geophysical Research: Solid Earth, v. 124, p. 4545-4565.

Sivakugan, N., Das, B.M., Lovisa, J., and Patra, C.R., 2014, Determination of $c$ and $\phi$ of rocks from indirect tensile strength and uniaxial compression tests: International Journal of Geotechnical Engineering, v. 8, p. 59-65.

Zhang, X.-P., Wong, L.N.Y., Wang, S-J., and Han, G.-Y., 2011, Engineering properties of quartz mica schist: Engineering Geology, v. 121, p. 135-149. 